\title{
How to Teach Motivating and Hands-On Laboratory and Field Courses in a Virtual Setting
}

\author{
By Mirjam S. Glessmer
}

Laboratory and field courses are designed to help students achieve many different learning outcomes simultaneously. Traditionally, conflating learning outcomes from a specific lab experiment or field trip at a distinct location has not been a problem. But with current restrictions surrounding in-person teaching and travel, it has become necessary to find alternative ways of achieving those learning outcomes. One way to do that is by disentangling procedural skills from factual or conceptual contexts and interpersonal aspects, and addressing them individually through separate activities.

In the following, I present suggestions for hybrid activities to replace traditional learning scenarios that we cannot easily replicate online. These suggestions work both in fully virtual settings and in hybrid ones, where some of the students attend physically while others join virtually.

\section{Addressing Learning}

Outcomes Independent of

Their Traditional Contexts

Students are experiencing an especially challenging time right now, with disruptions of routines due to COVID-19. They are often both lonely and overwhelmed. With hardly any contact with their peers and instructors, it is difficult to build a support network in which they can strive both socially and professionally. Interacting mostly via electronic devices and not being able to spend a solid amount of time in a designated physical learning environment makes it hard for them to feel like they are on their way to becoming oceanographers.
This is also a challenging time for instructors. Transitioning to online or hybrid teaching requires enormous effort. Many of the courses that were especially enjoyable to teach "before" and that students commonly worked hardest in and enjoyed the most have now become our biggest headache: laboratory and field courses.

Student labs often require sophisticated instruments and intricate health and safety measures, and field courses include travel to specific locations. For obvious reasons, many experiments cannot be done at home, nor can the fieldwork experience be easily replicated without the ability to travel. It is sometimes difficult to see how equivalent learning can be facilitated in a virtual setting other than through simulations, videos, or video streams, which seem like a pale shadow of "the real thing." But because laboratory courses as well as field courses serve multiple goals simultaneously, we can address many of them if not together, then at least sequentially. Clearly formulating detailed learning outcomes lets us separate them from the context in which they were traditionally taught. Fundamental factual or conceptual knowledge can easily and straightforwardly be conveyed virtually by means of video streams, conferences, or classical textbooks. Learning outcomes like developing experimental skills, observing a phenomenon, or writing reports can be taught online if one thinks a bit outside the box; instructors need to find ways to disconnect the learning outcomes from their traditional complex settings and address them in ways that students are able to absorb at home or wherever they currently happen to be. Even goals like supporting the building of professional identities, developing intrinsic motivation, and creating a network of peers can be achieved online. Ultimately, there are only a few learning outcomes that are difficult or impossible to imagine happening in the students' homes and that we might have to accept will not happen in a fully virtual class, such as those related to physically handling toxic substances or expensive instrumentation, or those requiring sensory experiences like a moving ship or the smell of certain chemicals.

\section{Using Home Experiments for Laboratory Experiences}

Home experiments can be conducted using easily available household items (or possibly materials that can be safely and cheaply sent to students, if you want to get fancy). Well-chosen home experiments permit exploration of scientific concepts as well as practice of skills, for example, conducting experiments following protocols, interpreting observations, or writing lab reports according to given standards, even in asynchronous settings where instruction might happen through written materials or videos.

Using home experiments in a synchronous setting provides additional opportunities. Students can conduct experiments via video conferences or voice calls. Both make them observe more closely because they need to describe to each other what they see in order to be able to practice discussing observations with peers, conduct- 
ing scientific conversations, and convincing others of their point of view. Home experiments can be combined with more complex experiments streamed from the laboratory and thus bridge the gap between theoretical learning and laboratory experience. Ideally, students can perform simplified versions of an experiment the instructor is presenting, or experiments that highlight relevant aspects of the instructor's experiment. For example, I have streamed experiments that show the influence of Earth's rotation on the behavior of fluids while students looked at a non-rotating case of the same process in their own home. This experiment led to fruitful discussions of similarities and differences-much more so than when we previously assumed that the nonrotating case was easy and boring, and went straight to the rotating case.

\section{Using Local Excursions for Field Experiences}

Local excursions are mini adventures that students embark upon individually, right outside their homes. Students are asked to go outside to observe a phenomenon, either with specific instructions ("find a hydraulic jump," which can be observed in every rain gutter or even in a kitchen sink) or as a more open exploration related to the topic of interest ("find evidence of phase transitions"; examples include clouds forming and changing shape, frost flowers growing on grass or leaves on the ground, icicles hanging from a roof). It is important to give students the opportunity to make the transfer from textbooks, lectures, or videos to the real world they live in and experience every day.

Local excursions can happen asynchronously, with results documented in writing and shared via a learning management system or social media. They can also be done synchronously but individually or in small groups, with observations reported back and discussed by the whole class. Using, for example, a 60-minute lunch break in a long virtual day for a local excursion has the added advantage that it

\section{BOX 1. EXAMPLES OF HOME EXPERIMENTS} AND LOCAL FIELD TRIPS

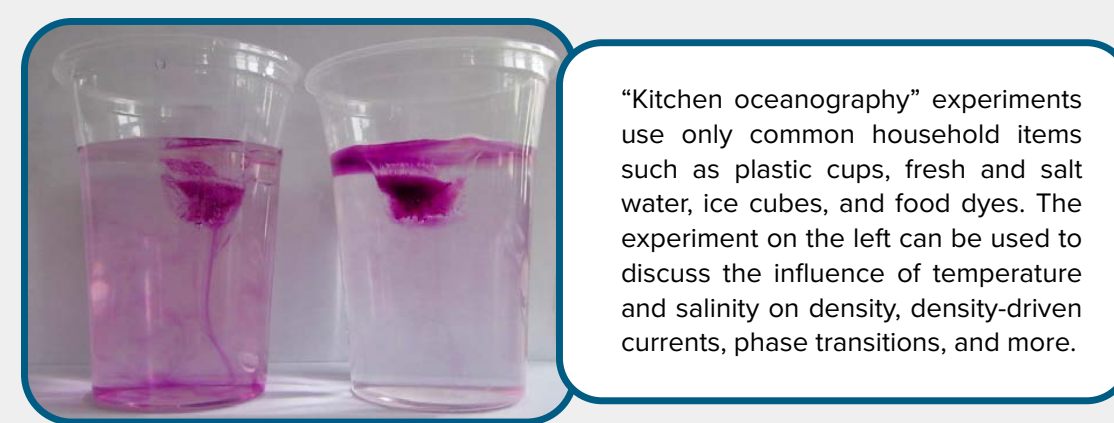

Video conferences with live-streamed complex experiments presented by the instructor while simpler experiments are run simultaneously by students at their homes provide a tool to give students a laboratory experience. In this case, I am running a rotating experiment (shown in side view and from above [upper left corner of screen filmed by two devices logged into the video conference]), while students conduct the same non-rotating experiment in a mug at home during our video conference.
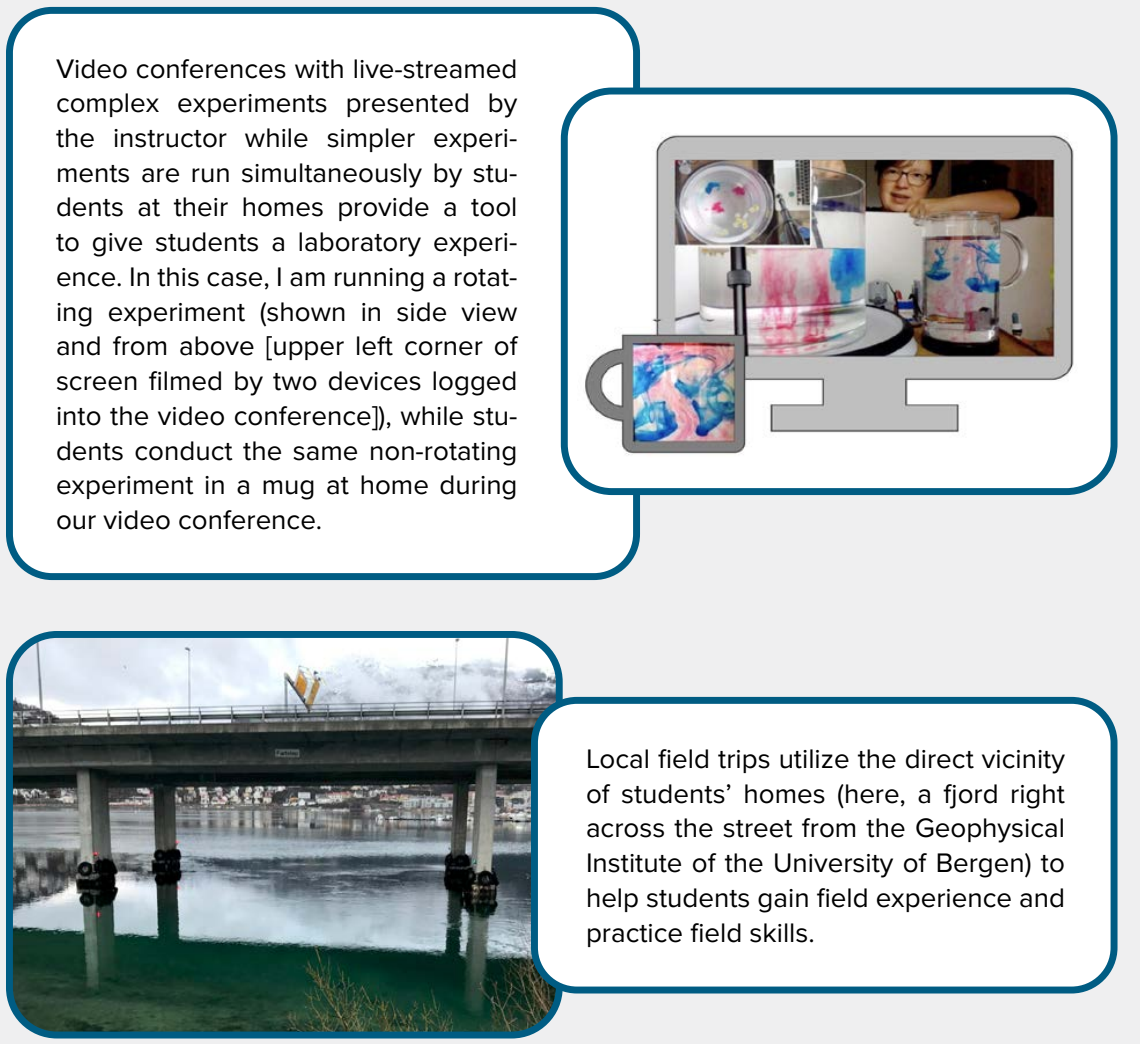

Interesting oceanographic phenomena can be observed anywhere and anytime. Shown here are waves on a puddle in the street as an example for oceanographic observations that do not require access to the ocean or even a lake or river.

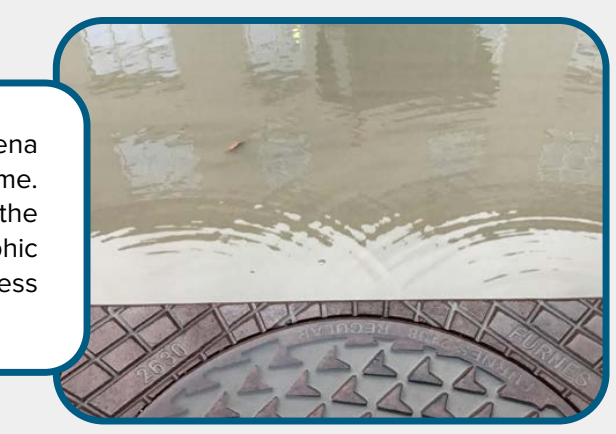

For inspiration, a collection of my favorite physical oceanography home experiences ("24 days of \#KitchenOceanography") can be found at

https://mirjamglessmer.com/24daysofkitchenoceanography/ 
BROADER IMPACTS ACTIVITIES SUCCESS STORIES

\author{
A Call for \\ Short Articles
}

Share a successful outcome of a "broader impacts" activity as well as any lessons learned during the project's development and execution. We are interested in compiling stories that may serve as templates for other researchers who are embarking on education and public outreach projects.

Follow the instructions for Commentaries, Meeting Reports, and Ocean Education and Ocean Policy articles at:

https://tos.org/ oceanography/guidelines

Questions?

Contact Ellen Kappel at

ekappel@geo-prose.com

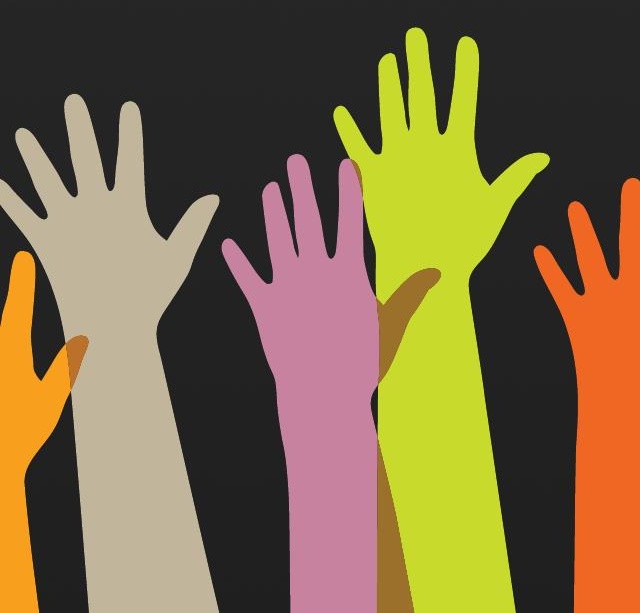

gets students out the door with a purpose, providing both motion and oxygen. It lets them experience success because the limited time proved long enough to have lunch, go outside, find a phenomenon, take a picture, upload it, and write one or two sentences about how it relates to the question. Local excursions also help build students' identities as oceanographers, because they start seeing the world with new eyes, different from the way they saw it before, and the way other people see it. This helps them feel that they are becoming experts in the field while also reminding them of concepts from class every time they are outside or see water in their water bottles or sinks.

\section{Psychological Needs \\ and Motivation}

The activities suggested above foster motivation by helping fulfill three basic human needs: feeling competent, autonomous, and related (Ryan and Deci, 2017). A feeling of competence is achieved when students successfully master new tasks, like conducting a home experiment or observing a process that they previously only knew about theoretically. Autonomy is experienced when students themselves choose how to conduct an experiment or which question deserves their focus. A feeling of relatedness is especially important for students in these times of isolation when they are studying by themselves in their homes. It is crucial that students be given the opportunity to make personal connections and build community, for example, by sharing pictures and results on social media and receiving positive feedback and encouragement from peers, friends, family, or even strangers-or by video conferencing that includes informal discussions and a view of the instructor's surroundings rather than just a virtual background. Showing ourselves as "real people" is important for other reasons, too. As instructors, we become the "face" of a subject, the interface through which students relate to the content we teach. We might also be among the very few role models working in their chosen profession that students have access to at the moment.

Lastly, materials developed now are not only a quick fix to bridge the time until we can go back to "normal." Even when in-person teaching will be possible again, hybrid or virtual materials can serve to better prepare students for in-person experiences, or they can be used as backup. Most importantly, the current challenge provides a great opportunity to change the exclusionary nature of lab and field work by reducing some of the current barriers, for example, accessibility issues, financial burdens, and harassment (Giles et al., 2020). Developing hybrid and virtual courses that accomplish the same learning outcomes as traditional courses might contribute to providing inclusive teaching in oceanography. @

\section{REFERENCES}

Giles, S., C. Jackson, and N. Stephen. 2020. Barriers to fieldwork in undergraduate geoscience degrees. Nature Reviews Earth \& Environment 1:77-78, https://doi.org/10.1038/s43017-020-0022-5.

Ryan, R.M., and E.L. Deci. 2017. Self-Determination Theory: Basic Psychological Needs in Motivation, Development, and Wellness. Guilford, New York.

\section{AUTHOR}

Mirjam S. Glessmer (mirjam.glessmer@uib.no) is Adjunct Associate Professor, Geophysical Institute, University of Bergen, Norway. 